\title{
Validation of Multicultural Counselling Competencies Scale among Malaysian Counsellor Trainees: A Confirmatory Factor Analysis
}

\author{
Amat, S. ${ }^{1}$ \\ Bakar, A. Y. A. ${ }^{2}$ (D) \\ Sahid, S. ${ }^{3}$ \\ Mahmud, M. I. ${ }^{4}$ \\ Shah, K. M. ${ }^{5}$ \\ Karim, D. N. F. M. ${ }^{6}$
}

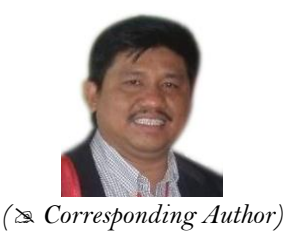

${ }^{0,3,4,5,6}$ Faculty of Education, Universiti Kebangsaan Malaysia, Bangi, Selangor, Malaysia.

Email: sallehba@ukm.edu.my Tel: +60193327394

Email:yazidss38@ukm.edu.my Tel: +60192246917

Email.sheerad@ukm.edu.my.Tel:+60198602169

Email:izrvan@ukm.edu.my Tel:+60192612059

Email: kamarul.mdshah@yahoo.com.my Tel: +60196218141

[Email: nissafuad2802@gmail.com Tel: +60179026392

\section{Abstract}

The competency of multicultural counselling is an aspect which needs to be mastered by a counsellor in order to provide good counselling services to clients especially when dealing with clients of different culture. The purpose of this research is to examine the validity and reliability of the Multicultural Counselling Competencies Scale which was developed based on the local culture by using confirmatory factor analysis (CFA). A total of 290 final year students participating in the first-degree counselling program from six public universities were selected randomly. The results of the analysis showed that the fit value for the comparative fit index (CFI), Tucker Lewis index (TLI), and normed fit index (NFI) respectively had fulfilled the fit value of 0.90 and above as suggested by the literature. The analysis also showed the average variance extracted (AVE) values for all three constructs were 0.669 (awareness), 0.764 (skills) and 0.642 (knowledge) respectively, indicating the validity convergent and discriminant reliability were achieved. CFA analysis has removed 7 out of 26 original items due to low loading factor. Overall, CFA analysis has successfully proven that competencies of multicultural counselling questionnaire as a multidimensional construct as it has been theorized and is appropriate for measuring the competencies of multicultural counselling in Malaysia.

Keywords: Counseling, Confirmatory factor analysis, Multicultural counselling, Multicultural counselling competencies scale.

Citation | Amat, S.; Bakar, A. Y. A.; Sahid, S.; Mahmud, M. I.; Shah, K. M.; Karim, D. N. F. M. (2020). Validation of Multicultural Counselling Competencies Scale among Malaysian Counsellor Trainees: A Confirmatory Factor Analysis. Journal of Education and e-Learning Research, 7(4): 373-379.

History:

Received: 12 August 2020

Revised: 10 September 2020

Accepted: 28 September 2020

Accepted: 28 September 2020

Licensed: This work is licensed under a Creative Commons

Licensed: This work is

Publisher: Asian Online Journal Publishing Group
Acknowledgement: All authors contributed to the conception and design of the study.

Funding: This study was supported by the Geran Fakulti Pendidikan, Funding: This study was supported by the Geran Fakulti Pendidikan,
Universiti Kebangsaan Malaysia (GGP-2019-025 and PP-FPEND-2020). The researchers would like to express their gratitude to all counselor trainees who were involved in this study.

Competing Interests: The authors declare that they have no conflict of interests.

Transparency: The authors confirm that the manuscript is an honest, accurate, and transparent account of the study was reported; that no vital features of the study have been omitted; and that any discrepancies from the features of the study have been omitte
study as planned have been explained.

Ethical: This study follows all ethical practices during writing.

\section{Contents}

1. Introduction 


\section{Contribution of this paper to the literature}

This research enhances the literatures collection of cross-cultural counselling in Malaysia. The main contribution is the adaptation of Multicultural Counselling Competencies Scale in the local context, which will enable the local researchers to utilize it in more settings, especially in the remote areas whereby the use of English language is limited.

\section{Introduction}

Malaysia is a multiracial country with people of various races, religions and descent (Hafzan \& Zolkepeli, 2018; Rafidah, 2017). Generally, nearly 32.6 million of Malaysia's population consists of three main races which are Malay, Chinese and Indians and other minorities. Similarly, the diverse indigenous peoples of Sabah and Sarawak make Malaysia more unique with its diversity of cultures. The various ethnic groups in Sabah and Sarawak are Kadazan, Bajau, Bajau, Murut, Bidayuh, Melanau and Iban (Nagaraj, Nai-Peng, Chiu-Wan, Kiong-Hock, \& Pala, 2015).

The diversity of these cultures affects the social lives of people in Malaysia (Hafzan \& Zolkepeli, 2018; Rosman, Khairol, Khairunesa, Atikah, \& Abd Rahman, 2016). This diversity also indirectly affects the counselling services in Malaysia. In such a multiracial country, counsellors or mental health service providers cannot avoid providing counselling services to individuals of different races and cultures.

The development of counselling services in Malaysia which began around the beginning of the '60s has been similar to that of other countries in the light of advances led by the counselling profession in America (Lloyd \& Aminah, 1987; Pope, 2000). The highlight of the recognition of counselling in Malaysia was when the government established a counselling act to regulate counselling services in Malaysia. Through this act only those who have received training from institutions of study recognized by the Board of Counsellors and subsequently registered with the Board of Counsellors can provide counselling services to the general public (Amla, Zuria, \& Salleh, 2010; Lembaga Kaunselor Malaysia, 2011).

The need for guidance and counselling services in Malaysia is increasingly gaining pace and covers all walks of life (Kamarul, Jasmi, \& Farah, 2017).

In conducting counselling, counsellors need to consider various aspects related to clients' cultures, such as religions, values, trust, gender, socio-economic status, political beliefs and sexual orientation (Choudhuri, SantiagoRivera, \& Garrett, 2012; Gonzalez-Voller, Crunk, Barden, Harris, \& Belser, 2020). The fact is that the counselling process itself takes place in a cultural context, means that then the meaning of counselling and the role of counsellor itself is different in various cultures. Cultural diversity understanding is fundamental to the needs of multicultural counselling to boost counsellors' self confidence in conducting counselling session effectively with clients of various cultures. Therefore, a counsellor needs to be knowledgeable and understand the culture of their clients. Counsellors' understanding in this aspect is often linked to the competencies of multicultural counselling.

The competencies of multicultural counselling can be related to the ability of the counsellor in integrating various theories, approaches as well as counselling assessments involving clients from various culture (Kamarul et al., 2017). Sue and Sue (2008) defined multicultural counselling and therapy as a helping process that utilizes established modalities and goals which are in line with clients' life experiences and cultural values. The competencies of multicultural counselling are more related to how interpretations are made by the counsellor towards issues or problems brought by the clients. Efficient counsellors should be working effectively and are sensitive to various clients from different cultures. The competencies of multicultural counselling are also related to the ability of counsellors to understand the uniqueness of each client who comes from a various culture where it influences different views or perspectives for each individual (Stuart, 2004).

The fact is that in understanding these mental health issues, counsellors can't afford to escape from seeing the issues from a cultural perspective. This is because something which is considered as a problem in one culture may not be considered as a problem in other culture which means those problems are defined differently among cultures. Hence, cultural context understanding towards illness related to mental health is imperative for assessment and clinical treatment objectively (American Psychiatric Association, 2013; Choudhuri et al., 2012).

The competencies of multicultural counselling are required by counsellors who work with clients of various culture (Maizatul, Rusnani, \& Sidek, 2017). It starts with understanding clients' background which is different from counsellors. It will be easier for counsellor to understand clients' problem by understanding their culture. Cultural understanding and the combination of theories and counselling approaches will cause counsellor to be more efficient in handling counselling sessions, especially when dealing with various clients. Choudhuri et al. (2012) emphasized that all the professionals involved in helping professional such as counsellors and psychologist have developed a guideline that focuses and commits towards client of various culture.

Overall, multicultural counselling competencies have been conceptualized as the awareness, knowledge and skills required by counsellors to work effectively with clients of various culture. Concept and the background of this multicultural counselling competencies were discussed extensively in the literature (Arredondo et al., 1996; Fietzer, Mitchell, \& Ponterotto, 2018; Hays, 2020; Singh, Nassar, Arredondo, \& Toporek, 2020; Derald Wing Sue, Arredondo, \& McDavis, 1992; Sue \& Sue, 2008; Worthington, Soth-McNett, \& Moreno, 2007). Arredondo et al. (1996) have affirmed that awareness about our own culture and sensitivity towards cultural inheritance is important in order to become a competent counsellor.

Thus, to provide professional counselling services, counsellors need to have good multicultural counselling competencies (Dameron, Camp, Friedmann, \& Parikh-Foxx, 2020; Malone \& Ishmail, 2020; Salleh et al., 2013). There has been countless research on the importance of enhancing multicultural counselling competencies especially among trainee counsellors to prepared themselves in dealing with clients of various culture (Dini, 2012; Fuertes, Bartolomeo, \& Nicols, 2001; Gonzalez-Voller et al., 2020; Lembaga Kaunselor Malaysia, 2011; See \& Ng, 2010). These cultural competencies aspect is being emphasized in the counselling curriculum in Malaysia (Lembaga Kaunselor Malaysia, 2011; Sumari \& Jalal, 2008). However, the measurement of the competencies of this multicultural counselling in local culture is still limited. 
There is still not much research done regarding multicultural competencies in Malaysia as compared to the west (Kamarul \& Salleh, 2010; Maizatul et al., 2017; Rafidah, 2017; Salleh et al., 2013). Some local researchers have adapted psychological tests from the west for local use. The problem is that instruments used in the west are not well suited for measuring the local cultural constructs (Rusnani \& Mohd, 2017). There are even some terms or constructs in the instrument that do not fit into the local culture.

Although instruments from the west have good reliability they can only be used in the west as it suits the culture of the people there. However, most of the instruments are often used arbitrarily in the local culture in the measurement of psychological aspects (Salleh, Mhd, Wan, Zuria, \& Ku, 2014). In fact, in some translation cases, the translation process does not take into account the local culture as a whole (Aden et al., 2020; Salleh et al., 2013). For instance, the item "I go to the church every week" might not be suitable for Muslims as they do not attend church. Thus, the content validity aspect should also be considered in the translation of foreign benchmarks which will be used in the local culture.

The questionnaires or foreign psychological tests used were not able to provide accurate information due to the occurrence of cultural bias when the respondent responded to the questions given. This might be closely related to different perceptions or interpretations of individuals who responded to the questionnaires based on different culture and education than the original target population from the west (Aden et al., 2019; Ibrahim, Che Din, Amit, Ghazali, \& Mohd Safien, 2019; Kim \& Zabelina, 2015; Weeks, Swerissen, \& Belfrage, 2007). The use of psychological tests that focus on a culture can even lead to various implications especially in making interpretations of the obtained information (Kim \& Zabelina, 2015; Mhd Subhan et al., 2018). Therefore, it is imperative that psychological tests are provided in a language spoken by the clients. The construction of instruments for measuring the competencies of various cultures in Bahasa Melayu (Malaysian language) is highly encouraged.

The central gap in this study refers to the absence of reliable instruments or scales in measuring multicultural competence in the Malay language. This study proposes a new instrument that has been built through a thorough instrument construction process using only exploratory factor analysis (EFA) to determine the number of items and constructs required. The number of items for each construct was studied to ascertain the fitness model of the instrument using confirmatory factor analysis (CFA).

Thus, the purpose of this research is to evaluate the validity and reliability of the multicultural survey instrument which has been developed for the use of counselling teachers in Malaysia (Aden et al., 2020; Salleh et al., 2013) In this research, the researcher will examine the psychometric properties of Malaysia multicultural competencies for the use of public universities trainee counsellors in Malaysia. Other than that, it will also determine whether the instrument produced is a multidimensional construct by using confirmatory factor analysis (CFA). It can be concluded that the main contribution of this study is to determine the psychometric properties of the Multicultural Counselling Competencies Scale in Malaysian cultures, especially in determining multicultural competence among Malaysian counsellors. The validity and reliability of the scale were determined rigorously using the CFA.

\section{Methodology}

This research used the survey method approach to evaluate and confirm the instrument of multicultural counselling competencies among trainee counsellors. Confirmatory factor analysis was used to confirm the dimension that forms the construct of multicultural competencies. The process of confirmation is to reaffirm the validity and reliability of the multicultural counselling competencies instrument built among the trainee counsellors in public university in Malaysia.

\subsection{Instrument}

A set of questionnaires called "Multicultural Counselling Competencies Scale" was used to identify the level of counselling competencies among counselling teachers from secondary school in Malaysia. It was developed by taking into consideration the suitability towards the culture and surrounding of Malaysian community (Salleh et al., 2013). This instrument is built based on the theory, literature review and the opinion from the experts in the field of counselling and multicultural counselling (Constantine \& Ladany, 2001; Pedersen, 2002; Singh et al., 2020; Sodowsky, 1996; Sue \& Sue, 2008) as well as counselling practitioners (Marshall \& Rossman, 2016; Merriam, 2001; Sidek, 2005).

The construction of this instrument began with qualitative information to understand the construct of multicultural counselling competencies in Malaysia (Ahmad, 2008; Bogdan \& Biklen, 2003; Sidek, 2005). An indepth interview was conducted to understand the concept, dimension or construct for the construction of items related to multicultural counselling competencies (Bogdan \& Biklen, 2003). Salleh et al. (2013) reported that eleven experts were interviewed to obtain themes related to multicultural counselling competencies based on perspective and culture of the Malaysian community in the practice of counselling in Malaysia.

A total of 115 items were created in the early stage. The research team have revised each item in reference to the expert's opinion. These items were then evaluated by the expert resulting in 73 items in total. A series of discussions were conducted to ensure the accuracy and appropriateness of each item. The items were also checked to make sure that no items overlapped or had an inaccurate or double meaning (Aden et al., 2020; Mohd, 2005; Murphy \& Davidshover, 1998; Sidek, 2005).

After evaluation by panel of expert, 42 items were identified to measure the multicultural counselling competencies scale. The final questionnaires were distributed to 212 respondents which are also counselling teachers in a state in Malaysia. Several series of factor analysis using the Extraction Method: Principal Component Analysis (Hair, Black, Anderson, \& Tantham, 2006; Tabachnick \& Fidell, 2001) were conducted using the SPSS software ver. 20. The final analysis managed to yield three main constructs with 26 items representing three domains or constructs namely awareness, knowledge and skills and they were constructed in accordance with the theory of multicultural counselling and the proposed model of multicultural counselling competencies (Sue, Ivey, \& Pedersen, 1996). 
The division of items for each construct is as follows; awareness with items 1-8, knowledge with items 9-17 and skill with items 18-26. The Cronbach alpha for the reliability analysis also showed high reliability value which is .92. The 26-items questionnaires were distributed using the 11-point scale range from 1 as "Strongly Disagree" to 11 as "Strongly Agree".

\subsection{Sample}

Malaysia offers counselling programs ranging from the level of bachelor's degree, master's level and doctorate level. The cluster random sampling was used due to the population is large and involving all public universities in Malaysia (Fraenkel, Wallen, \& Hyun, 2012). The population for this research is final year students who are currently studying for the bachelor's degree.

A review by the Malaysian Board of Counsellors shows that there are nine public universities that offer counselling training programs at the bachelor's degree. The total number of final year's students in the research population is 523. The research team has reached out for selected universities for approval and cooperation in order to get the final year students in the counselling programs to be involved in the research.

Random sampling technique has been used to meet the requirements in operating the confirmatory analysis factor analysis (CFA). The minimum number of sample size which eligible for CFA analysis is 200 (Hair, Black, Babin, \& Anderson, 2010). Out of nine universities, six public universities were randomly selected using cluster sampling method that involve 290 students $(n=290)$. Each student from the selected universities volunteered to participate in this research. The breakdown of respondents based on each university is as follows; 1 . University of Malaya, $\mathrm{n}=20$; 2. International Islamic University of Malaysia, $\mathrm{n}=53$; 3. University of Sarawak, $\mathrm{n}=49$; 4. Sultan Idris University of Education, $\mathrm{n}=29 ; 5$. University of Terengganu Malaysia, $\mathrm{n}=87$; and 6. University of Islamic Sciences Malaysia, $\mathrm{n}=52$.

\subsection{Data Analysis}

CFA analysis used in this research is one of the parametric statistical analysis that uses the probability sampling technique (Hair et al., 2010). Data collected were analyzed using the SPSS ver. 22 and AMOS ver. 22. Data cleaning and screening have been conducted to avoid misinterpretation of "output", mainly involving missing values.

\section{Findings \& Discussions}

The main objective of this research is to determine the validity and reliability of a built instrument (Salleh et al., 2013) by using the confirmatory factor analysis (CFA) among trainee counsellors in Malaysia. This analysis will ascertain a fitness model for the instrument that has been built and to find out the final item count guided by the model. Convergent validity and discriminant validity analysis were carried out in order to determine all the resulting domains for this instrument to be statistically acceptable.

\subsection{Confirmatory Factor Analysis (CFA)}

Figure 1 is the measurement model through the first stage of CFA analysis. The first level CFA was performed to test the fitness model if the multicultural competence dimensions were measured as unidimensional whereas the second stage of CFA Figure 2 was performed to determine the model fitness if multicultural competence was measured as a multidimensional construct as interpreted. The findings of the analysis show that the measurement model has met the required index fit values. The fit value for Comparative Fit Index (CFI), Tucker Lewis Index (TLI), and Normed Fit Index (NMI) all met the fit value suggested by the literature which is above 0.90 respectively. While the index value of RMSEA is less than 0.08, and Chi $S q / d f$ less than 5.0 indicates that the fit value criteria of each index category have been met. The loading factor of all items ranging from 0.68 to 0.91 indicates the uni-dimensionality criteria of the measurement scale for all three constructs of awareness, skills and knowledge has been met (Hair et al., 2010; Sahoo, 2019).

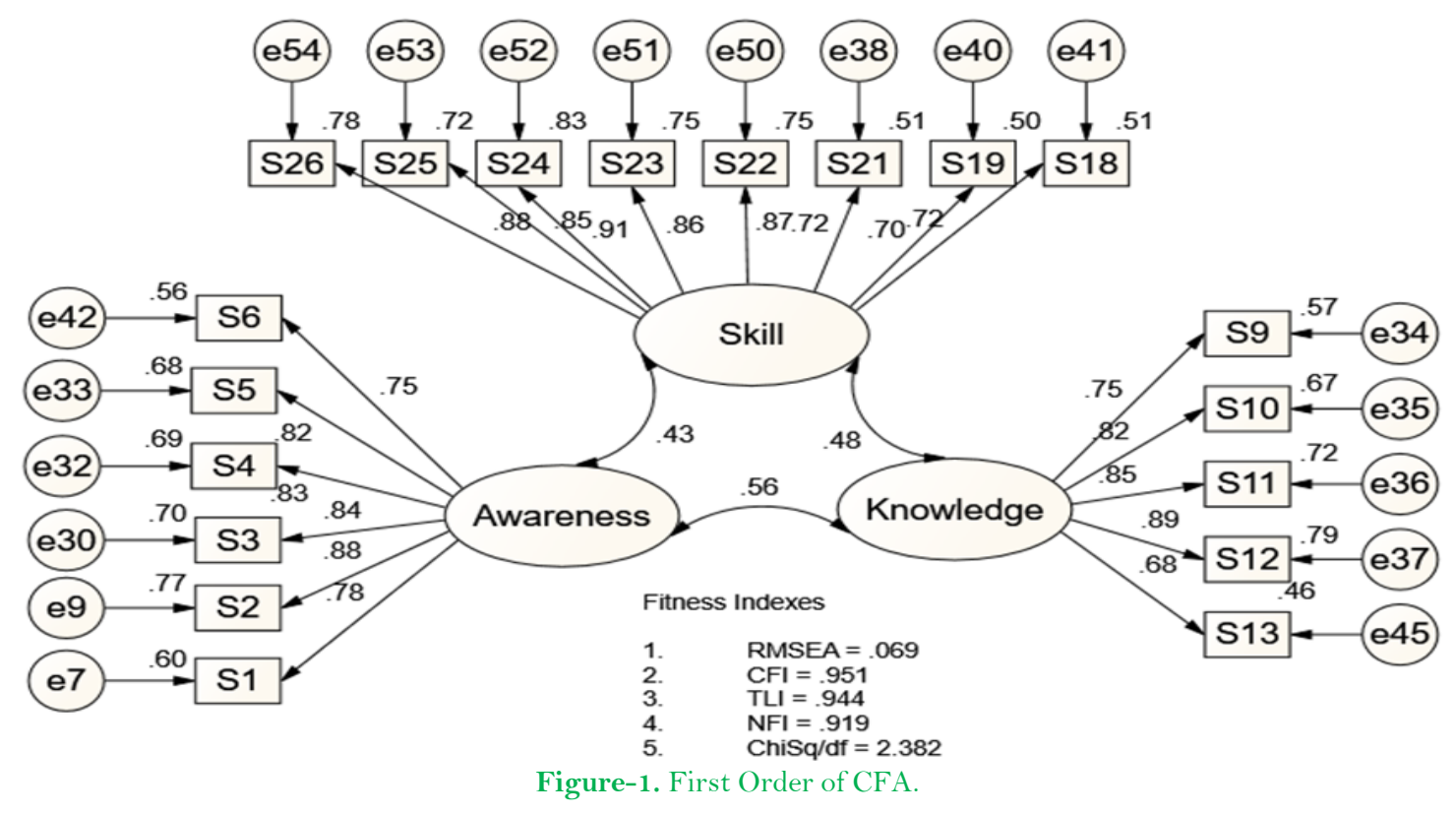

Figure 2 is the result of the second level CFA. The results of the index values are the same as those produced in the first level CFA. Uni-dimensionality criteria items are met when every estimation method has a loading factor of $\geq 0.70$. The result of CFA analysis shows a few items that are removed without giving negative impact to the 
original instrument construct. Initially, there were 26 items and CFA analysis has removed 7 items due to low loading factor. The final item for this instrument is only 19 items. Overall, this research has succeeded in reducing the number of items in the developed instrument. The first construct of "awareness" is represented by the items number 1, 2, 3, 4, 5, and 6. The "knowledge" construct is represented by the items number 9, 10, 11, 12, and 13. Finally, the "skill" construct is represented by the items number 18, 19, 21, 22, 23, 24, 25 and 26. This is in line with measurements in the psychological field where small number of items help respondents to respond easily (Mhd Subhan et al., 2018; Salleh et al., 2014).

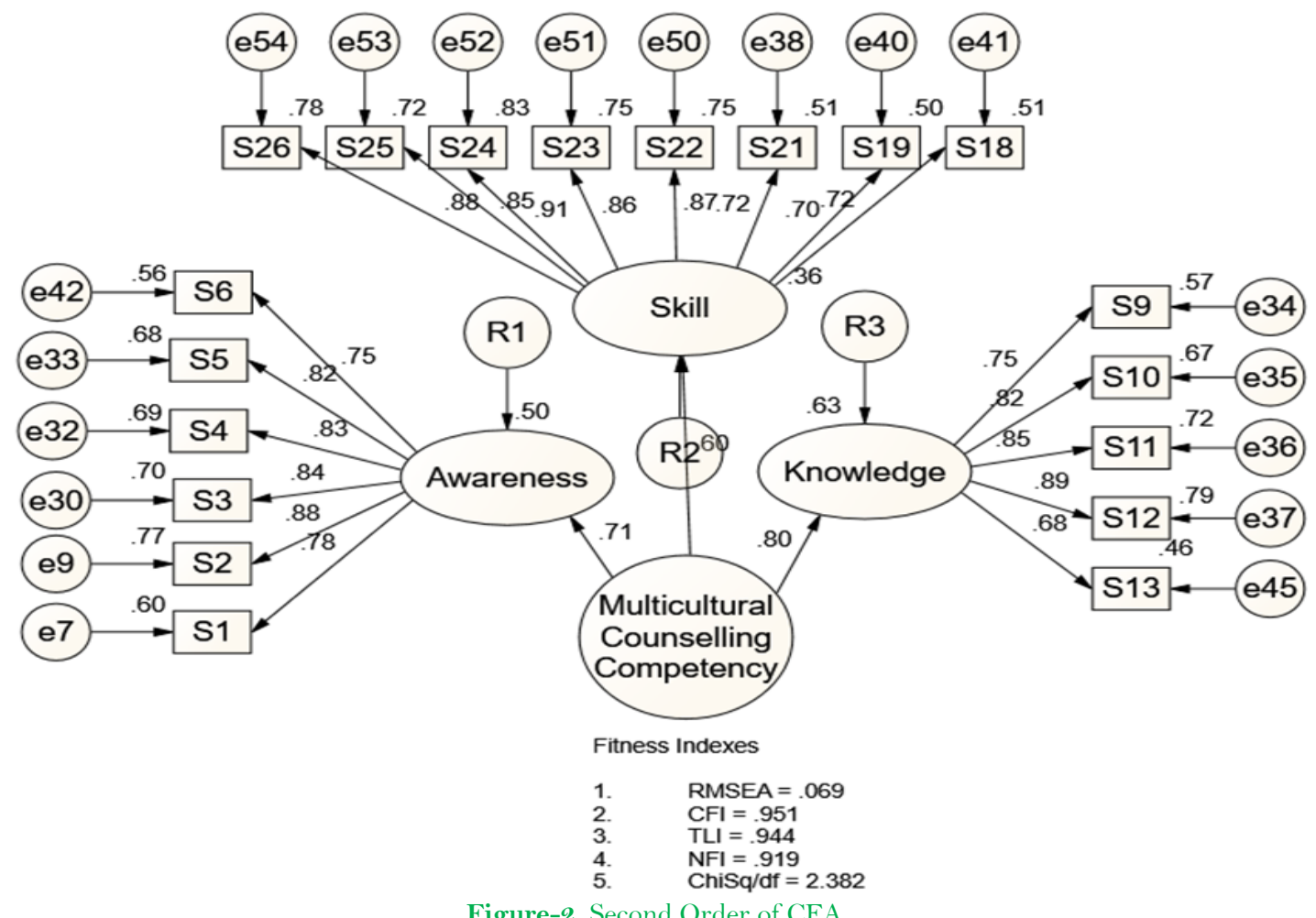

\subsection{Reliability and Validity}

Table 1 is the summary of reliability analysis and validity of multicultural competency constructs. Based on the table, the average variance extracted (AVE) values for awareness, skill and knowledge are 0.669, 0.764 and 0.642 respectively which met the criteria (AVE $\geq 0.50)$ to show the convergent and discriminant validity (Hair et al., 2010; Sahoo, 2019; Zainudin, 2012). While the correlation values between the three constructs were 0.45, 0.48, and 0.56; below 0.85 indicates that the discriminant validity has been met (Pedhazur \& Schmelkin, 1991; Sahoo, 2019; Zainudin, 2012) where each construct is different from one another. All three Cronbach Alpha (CA), Composite Reliability (CR), and Average Variance Extracted (AVE) criteria have been met to prove that multicultural competency instruments are valid and reliable to be used for future research.

This research supports previous local research which emphasized that the measurement of multicultural competencies in Malaysia also involves several key factors. In this matter, skills, competency and knowledge are important aspects in measuring a counsellor's competency when dealing with multicultural issues (Kamarul et al., 2017; Kamarul \& Salleh, 2010; Maizatul et al., 2017; Salleh et al., 2013). Psychological test of good validity and reliability in the local culture will allow for more accurate interpretations towards issues related to the local culture itself. It does not depend solely on the suggested interpretations by the instruments' developer which are mostly based on western culture (Aden et al., 2019, 2020; Ibrahim et al., 2019; Kim \& Zabelina, 2015).

Table-1. Reliability and validity of cross-cultural competency construct.

\begin{tabular}{|c|c|c|c|c|}
\hline Main Construct & Loading Item & $(\mathrm{CA}) \geq 0.70$ & $(\mathrm{CR}) \geq 0.60$ & $\mathrm{AVE} \geq 0.50$ \\
\hline \multirow{6}{*}{ Awareness } & 0.75 & \multirow{6}{*}{0.92} & \multirow{6}{*}{0.924} & \multirow{6}{*}{0.669} \\
\hline & 0.82 & & & \\
\hline & 0.83 & & & \\
\hline & 0.84 & & & \\
\hline & 0.88 & & & \\
\hline & 0.78 & & & \\
\hline \multirow{8}{*}{ Skill } & 0.88 & \multirow{8}{*}{0.94} & \multirow{8}{*}{0.941} & \multirow{8}{*}{0.764} \\
\hline & 0.85 & & & \\
\hline & 0.91 & & & \\
\hline & 0.86 & & & \\
\hline & 0.87 & & & \\
\hline & 0.72 & & & \\
\hline & 0.70 & & & \\
\hline & 0.72 & & & \\
\hline \multirow{5}{*}{ Knowledge } & 0.75 & \multirow{5}{*}{0.90} & \multirow{5}{*}{0.899} & \multirow{5}{*}{0.642} \\
\hline & 0.82 & & & \\
\hline & 0.85 & & & \\
\hline & 0.89 & & & \\
\hline & 0.68 & & & \\
\hline
\end{tabular}




\section{Conclusion}

As a whole, CFA analysis has proven that multicultural competencies questionnaire is a valid and reliable instrument for measuring multicultural competencies among trainee counsellors in Malaysia. The loading factors of all items showed that the uni-dimensionality criteria of the measurement scale for all three constructs of awareness, skills and knowledge has been met. Next, the second stage of CFA performed has successfully demonstrated that the multicultural competencies model fitness is measured as a multidimensional construct as interpreted. It has proven that the questionnaires have three constructs to measure the multicultural competencies.

In terms of validity and reliability, all three Cronbach Alpha (CA), Composite Reliability (CR), and Average Variance Extracted (AVE) criteria have been met to demonstrate that the instrument of multicultural competencies is valid and reliable. This analysis has successfully proven that the questionnaires have good psychometric properties despite having only nineteen items compared to the initial 26 items. This means that this research has succeeded in summarizing the developed instrument to test the same constructs. Overall, the instrument can be used in other researches regardless the sample used. This is due to the instrument being validated in terms of reliability and validity using a statistical approach that is able to validate the instrument with great accuracy.

\section{References}

Aden, E., Amat, S., Mahmud, M. I., Bakar, A. Y. A., Ghazali, N. M., \& Annuar, A. (2019). Split-half analysis: Measurement of validity and reliability of the career counselling self-efficacy scale (CCSES) in Malaysian public universities. International Journal of Innovation, Creativity and Change, 7(7), 1-15.

Aden, E., Amat, S., Mahmud, M. I., Bakar, A. Y. A., Ghazali, N. M., \& Annuar, A. (2020). Initial validation of the career counselling selfefficacy scale in Malaysian public universities. International Journal of Psychosocial Rehabilitation, 24(6), 7147-7156.

Ahmad, J. J. (2008). The use of reality therapy among counselors in Malaysia. Doctor of Philosophy thesis. Universiti Kebangsaan Malaysia.

American Psychiatric Association. (2013). Diagnostic and statistical manual of mental disorders (5th ed.). Arlington, VA: Author.

Amla, S., Zuria, M., \& Salleh, A. (2010). School guidance and counseling. Bangi, Malaysia: UKM Publishers.

Arredondo, P., Toporek, R., Brown, S. P., Jones, J., Locke, D. C., Sanchez, J., \& Stadler, H. (1996). Operationalization of the multicultural counseling competencies. Journal of Multicultural Counseling and Development, 24(1), 42-78.

Bogdan, R. C., \& Biklen, S. K. (2003). Qualitative research for education: An introduction to theories and methods (4th ed.). Boston: Allyn and Bacon.

Choudhuri, D., Santiago-Rivera, A., \& Garrett, M. (2012). Counselling Eீ diversity. Belmont, CA: Brooks/Cole.

Constantine, M. G., \& Ladany, N. (2001). New visions for defining and assessing multicultural counseling competence. Dlm. J.G. Casas, L.A. Suzuki \& C.M. Alexander (Eds.), Handbook of Multicultural Counseling (2nd ed., pp. 482-498). Thousand Oaks, CA: Sage.

Dameron, M. L., Camp, A., Friedmann, B., \& Parikh-Foxx, S. (2020). Multicultural education and perceived multicultural competency of school counselors. Journal of Multicultural Counseling and Development, 48(3), 176-190. Available at: https://doi.org/10.1002/jmcd.12176.

Dini, F. B. (2012). Perception and understanding of counselor trainees on multicultural counseling in Malaysia. Paper presented at the Proceeding Asia Pacific RIM International Counseling Conference (2012).

Fietzer, A. W., Mitchell, E., \& Ponterotto, J. G. (2018). Multicultural personality and multicultural counseling competency in counselor trainees. Counselor Education and Supervision, 57(2), 82-97. Available at: https://doi.org/10.1002/ceas.12095.

Fraenkel, J. R., Wallen, N. E., \& Hyun, H. H. (2012). How to design and evaluate research in education (8th ed.). New York: McGraw-Hill Education.

Fuertes, J. N., Bartolomeo, M., \& Nicols, C. M. (2001). Future research directions in the study of counselor multicultural competency. Journal of Multicultural Counseling and Development, 29(1), 3-12. Available at: https://doi.org/10.1002/j.2 161-1912.200 1.tbo0499.x.

Gonzalez-Voller, J., Crunk, A. E., Barden, S. M., Harris, S., \& Belser, C. T. (2020). A preliminary longitudinal study of multicultural competence in counselor education. Journal of Counseling छे Development, 98(3), 308-318. Available at: https://doi.org/10.1002/jcad.12325.

Hafzan, O., \& Zolkepeli, H. (2018). Measurement of cultural diversity sensitivity among teachers using the MIS model (Developmental Model of Intercultural Sensitivity) by Bennett. Journal of Techno Social, 9(2), 1-12.

Hair, J. E., Black, W. C., Anderson, R. E., \& Tantham, R. L. (2006). Multivariate data analysis (5th ed.). Upper Saddle River, New Jersey: Prentice-Hall.

Hair, J. E., Black, W. C., Babin, B. J., \& Anderson, R. E. (2010). Multivariate data analysis (7th ed.). Upper Saddle River: Pearson.

Hays, D. G. (2020). Multicultural and social justice counseling competency research: Opportunities for innovation. Journal of Counseling $\mathcal{E}^{\circ}$ Development, 98(3), 331-344. Available at: https://doi.org/10.1002/jcad.12327.

Ibrahim, N., Che Din, N., Amit, N., Ghazali, S. E., \& Mohd Safien, A. (2019). Development and validation of Yatt suicide attitude scale (YSAS) in Malaysia. PloS one, 14(2), e0209971. Available at: https://doi.org/10.1371/journal.pone.0209971.

Kamarul, M. S., Jasmi, A. T., \& Farah, M. (2017). Efficiency of secondary school teachers in conducting various cultural coun seling services. The Social Sciences, $12(9), 1577-1584$.

Kamarul, M. S., \& Salleh, A. (2010). The issue of multicultural counseling in guidance and counseling services in Malaysia. Paper presented at the National Counseling Convention, Universiti Malaysia Terengganu, 13-15 June 2010.

Kim, K. H., \& Zabelina, D. (2015). Cultural bias in assessment: Can creativity assessment help? The International Journal of Critical Pedagogy, $6(2), 129-148$.

Lembaga Kaunselor Malaysia. (2011). Counselor code of ethics. Kuala Lumpur: LKM.

Lloyd, A. P., \& Aminah, H. (1987). Guidance and counseling in Malaysia. Kuala Lumpur: DBP.

Maizatul, M. H., Rusnani, A. K., \& Sidek, M. N. (2017). Self-perceived multicultural counselling competence among guidance and counselling teachers. Jurnal PERKAMA, 21(7), 114-132.

Malone, C. M., \& Ishmail, K. Z. (2020). A snapshot of multicultural training in school psychology. Psychology in the Schools, 1-18. Available at: $10.1002 /$ pits.22392.

Marshall, C., \& Rossman, G. (2016). Designing qualitative research (6th ed.). Thousand Oaks: SAGE.

Merriam, S. B. (2001). Andragogy and self-directed learning: Pillars of adult learning theory. New Directions for Adult and Continuing Education, Special issue(89), 3-14. Available at: https://doi.org/10.1002/ace.3.

Mhd Subhan, Mas'ud Zein, A., Mohd, H. Z. A., Sallehudin, A., Salleh, A., \& Abu, Y. A. B. (2018). Reliability of self-employment intentions instrument among international students in Indonesian university. International Journal of Engineering and Technology (UAE), 7(2), 76-79. Available at: https://doi.org/10.14419/ijet.v7i2.10.10960.

Mohd, M. K. (2005). Educational research methods. Kuala Lumpur: Dewan Bahasa dan Pustaka.

Murphy, K. R., \& Davidshover, C. O. (1998). Psychological testing, principles and application (4th ed.). New Jersey: Prentice Hall.

Nagaraj, S., Nai-Peng, T., Chiu-Wan, N., Kiong-Hock, L., \& Pala, J. (2015). Counting ethnicity in Malaysia: The complexity of measuring diversity. In: Simon P., Piché V., Gagnon A. (eds). Social Statistics and Ethnic Diversity. IMISCOE Research Series (pp. 143-173). Cham: Springer.

Pedersen, P. B. (2002). Ethnics, competence and other professional issues in culture-centered counseling. Dlm. P. B. Pedersen, J. G. Draguns, W. J. Lonner, \&J. E. Trimble (Eds.), Counseling Across Cultures (5th ed., pp. 3-27). Thousand Oaks, CA: Sage.

Pedhazur, E. J., \& Schmelkin, L. P. (1991). Measurement, design, and analysis: An integrated approach. Hillsdale, NJ: Lawrence Erlbaum Associates.

Pope, M. (2000). A brief history of career counseling in the United States. The Career Development Quarterly, 48(3), $194-211$. 
Rafidah, A. M. J. (2017). Perceived multicultural counseling competence of Malaysian counselors: An exploratory study. Journal of Multicultural Counseling and Development, 45(2), 127-148.

Rosman, M. Y., Khairol, A. K., Khairunesa, I., Atikah, Y., \& Abd Rahman, A. (2016). Factors influencing alumni donations at Malaysian public Universities. Paper presented at the Proceedings of the 28th International Business Information Management Association Conference - Vision 2020: Innovation Management, Development Sustainability and Competitive Economic Growth 2016. November 9-10, Seville, Spain.

Rusnani, A. K., \& Mohd, Y. A. (2017). Reliability and validity of the self-efficacy of multicultural counseling instrument (Translated Multicultural Counseling Self-Efficacy-Racial Diversity; MCSE-RD). Journal PERKAMA, 21(6), 97-1 13.

Sahoo, M. (2019). Structural equation modeling: Threshold criteria for assessing model fit, Subudhi, R.N. and Mishra, S. (Ed.), Methodological Issues in Management Research: Advances, Challenges, and the Way Ahead (pp. 269-276). Emerald Publishing Limited.

Salleh, A., Kamarul, M. S., Zuria, M., Amla, M. S., Rosseni, D., \& Mohd, I. M. (2013). Initial development and validation of multicultural counseling competencies Scale for Malaysian school counselors. Asian Social Science, 9(17), 144-152.

Salleh, A., Mhd, S., Wan, M. W. J., Zuria, M., \& Ku, S. K. J. (2014). Evaluation and psychometric status of the brief resilience scale in a sample of Malaysian international students. Asian Social Science, 10(18), 240-245.

See, C. M., \& Ng, K. M. (2010). Counseling in Malaysia: History, current status, and future trends. Journal of Counseling छ Development, 88(1), $18-22$.

Sidek, M. N. (2005). Testing and evaluation in counseling: Theory and application. Serdang: UPM Publishers.

Singh, A. A., Nassar, S. C., Arredondo, P., \& Toporek, R. (2020). The past guides the future: Implementing the multicultural and social justice counseling competencies. Journal of Counseling \& Development, 98(3), 238-252.

Sodowsky, G. R. (1996). The multicultural counseling inventory: Psychometric properties and some uses in counseling training. Dlm. G.R. Sodowsky \& T.C. Impara (Eds.), Multicultural assessment in counseling and clinical psychology (pp. 283-324). Lincoln, NE: Buros Institute of Mental Measurement.

Stuart, R. B. (2004). Twelve practical suggestion for achieving multicultural competence. Professional Psychology: Research and Practice, 35(1), 3-9. Available at: https://doi.org/10.1037/0735-7028.35.1.3.

Sue, D. W., Arredondo, P., \& McDavis, R. J. (1992). Multicultural counseling competencies and standards: A call to the profession. Journal of Counseling \& Development, $70(4), 477-486$. Available at: https://doi.org/10.1002/j.1556-6676.1992.tbo1642.x.

Sue, D. W., Ivey, A. E., \& Pedersen, P. B. (1996). A theory of multicultural counseling and therapy. Pacific Grove, CA: Brooks/Cole.

Sue, D. W., \& Sue, D. (2008). Counseling the culturally diverse: Theory and practice (5th ed.). New York: John Wiley.

Sumari, M., \& Jalal, F. H. (2008). Cultural issues in counseling: An international perspective. Counseling, Psychotherapy and Health, 4(1), $24-34$.

Tabachnick, \& Fidell. (2001). Using multivariate statistic (4th ed.). USA: Allyn \& Bacon.

Weeks, A., Swerissen, H., \& Belfrage, J. (2007). Issues, challenges, and solutions in translating study instruments. Evaluation Review, $31(2)$, 153-165. Available at: https://doi.org/10.1177/0193841 x06294184.

Worthington, R. L., Soth-McNett, A. M., \& Moreno, M. V. (2007). Multicultural counseling competencies research: A 20-year content analysis. Journal of Counseling Psychology, 54, 351-361. Available at: 10.1037/0022-0167.54.4.351.

Zainudin, A. (2012). A handbook on structural equation modeling using AMOS. Shah Alam (Malaysia): Publisher Universiti Teknologi MARA (UITM Press). 